\title{
SINGLE PULSE TWO-PHOTON LASER-ASSISTED REDUCTION OF BENZOPHENONE BY TRIETHYLAMINE TO FORM EXCITED BENZOPHENONE KETYL RADICAL
}

\author{
J. M. FIGUERA ${ }^{a}$, R. SASTRE ${ }^{b}$ A. COSTELA ${ }^{a}$, I. GARCIA-MORENO ${ }^{a}$, \\ M. T. AL-HAKAKK ${ }^{\mathrm{a}}$ and J. DABRIO ${ }^{\mathrm{b}}$. \\ a) Instituto de Química Física “Rocasolano", CSIC, Serrano 119, 28006 Madrid, \\ Spain. \\ b) Instituto de Ciencia y Tecnología de Polímeros, CSIC, Juan de la Cierva 3, \\ 28006 Madrid, Spain.
}

(Received 20 July, 1993)

\begin{abstract}
The pulsed laser photolysis at $308 \mathrm{~nm}$ of the benzophenone-triethylamine system in acetonitrile solution has been studied at room temperature. In the absence of triethylamine, phosphorescence emission of triplet benzophenone centred at $460 \mathrm{~nm}$ and with a lifetime of $\tau=27 \pm 1 \mu \mathrm{s}$ is observed. Addition of triethylamine results in quenching of the benzophenone phosphorescence. Quenching rate constants $\mathrm{k}_{\mathrm{Q}}$ have been determined from emission intensities and from experimental decay rate constants. The values $\mathrm{k}_{\mathrm{Q}}=(2.6 \pm 0.3) \times 10^{9} \mathrm{M}^{-1} \mathrm{~s}^{-1}$ and $\mathrm{k}_{\mathrm{Q}}=(4.0 \pm 0.5) \times 10^{9} \mathrm{M}^{-1} \mathrm{~s}^{-1}$, respectively, are obtained. On the addition of triethylamine, benzophenone phosphorescence diminishes and simultaneously a new emission with a fast decay rate and centred at $575 \mathrm{~nm}$ develops. This signal has been identified as emission from the excited benzophenone ketyl radical. A single pulse two-photon absorption mechanism responsible of the emission at $575 \mathrm{~nm}$ has been identified and a kinetic model based on this mechanism has been developed. The model gives a satisfactory quantitative account of both our experimental results and those reported in the literature (quantum yield of radical formation and behaviour of the system as photoinitiator).
\end{abstract}

KEY WORDS: Laser Photochemistry, two-photon excitation.

\section{INTRODUCTION}

The present interest in tailor-made photoinitiators for specific applications requires the prediction of the relationship between molecular structure and properties. Aromatic carbonyl compounds have been proposed as photoinitiators because of the ability of their triplet state, formed at high yield on ultraviolet irradiation, to abstract hydrogen atoms and produce radicals. ${ }^{1,2}$ In addition, photoinitiators containing aromatic carbonyl functions as chromophores have been widely studied in order to determine the behaviour of intermediaries which can play a significant role in free 
radical polymerization. ${ }^{3,4} \mathrm{~A}$ complete understanding of a chemical or photochemical reaction requires a detailed knowledge of any transient intermediary. A thorough comprehension of the reaction mechanism will provide the means to control the undesired processes that can take place.

The benzophenone photoreduction by amines has been studied for a long time. Part of the observations related to the present work were published in the classical papers of Cohen et al..$^{5-7}$ and of Wagner et al. ${ }^{8}$ Several authors have published reviews on the subject.9,10 The proposed mechanism for the photoreduction of benzophenone involves an electron transfer from amine to benzophenone followed by a proton transfer ${ }^{11,12}$ that forms the benzophenone ketyl radical; the possibility of an ion-pair or a charge transfer complex as intermediaries was included. The mentioned conclusions were arrived at before lasers were incorporated in the flash-photolysis techniques. Later studies accepted that spectral detection of a benzophenone anion or a amine cation warranted the intermediacy of a charge transfer process in the photoreduction process. The majority of the initial studies on the benzophenone (BZ)triethylamine (TEA) system, using nano- and pico-second techniques, were unable to provide evidence on the participation of polar intermediaries. ${ }^{13-16}$ Only Schaefer et al. ${ }^{17}$ reported the identification of a complex but the enormous amine concentrations used cast some doubts on its intermediacy under ordinary photoreduction conditions. More recently, Devadoss and Fesseden ${ }^{18}$ also favoured the mentioned mechanism, although based on indirect evidence. Gas phase results of Matsushita $e t$ $a l .{ }^{19}$ showed that neither the formation of a long lived complex nor the contribution of the solvent molecules are necessary for the hydrogen abstraction.

In most of the modern work the benzophenone ketyl radical $\left(\mathrm{BK}^{\circ}\right)$ has been analyzed by LIF, a second laser promoting the transition from the ground to the excited state of the radical. ${ }^{20-26}$ As far as we know only in one previous work the possibility of biphotonic absorption has been reported. ${ }^{27}$

In this work we have simultaneously followed the time integrated intensity of both benzophenone phosphorescence centred at $460 \mathrm{~nm}$ and fluorescence of the excited benzophenone ketyl radical at $575 \mathrm{~nm}$. Both emissions have been readily identified in this work from their spectra and lifetimes.

The data obtained have allowed us to report a case in which a single $308 \mathrm{~nm}$ laser pulse of modest energy (a few millijoules) is able to generate an excited benzophenone ketyl radical, in a solution of benzophenone and triethylamine in acetonitrile, through a process that may be defined as a two-photon single pulse assisted reaction. Evidence on the biphotonic character of the process is presented and a kinetic model based on those premises built. The model gives a satisfactory quantitative account of both the data here reported and those reported in the literature (quantum yield of radical formation and behaviour of the system as photoinitiator).

Although photo or laser-assisted reactive collisions is an extremely active field of research (see ref. 28 for a review), we are not aware of any well documented report of single pulse two-photon laser-assisted reaction in the liquid phase. 


\section{EXPERIMENTAL SYSTEM}

A home-made $\mathrm{XeCl}$ excimer laser supplying up to $40 \mathrm{~mJ}$ energy in $~ 12 \mathrm{nsec}$ FWHM pulses at $308 \mathrm{~nm}$ was used as the excitation source. A quartz beam splitter selected $\sim 10 \%$ of the laser output to be directed towards the $1 \mathrm{~cm}$ silica cell containing the solutions. A $1 \mathrm{~m}$ focal length spectrosil B spherical lens focused mildly the excitation light onto the cell and a $2 \mathrm{~mm}$ iris diaphragm placed before the cell selected the central part of the rectangular laser beam assuring spatial uniformity of the light illuminating the cell. The total energy of the pulse impinging in the cell was estimated as $\sim 1 \mathrm{~mJ}$. A part of the laser light passing through the beam splitter was collected by an optical fibre and directed towards a photodiode (RS-BPX-65). The signal from this photodiode was used for triggering the detection system. The luminescence (monitored at right angles to the exciting beam) was imaged, after the passage through a cut-off filter to eliminate $308 \mathrm{~nm}$ scattered light, onto the input slit of a monochromator (MacPherson-2035, $0.35 \mathrm{~m}$ ) and detected by a photomultiplier (EMI 9816-QB). The signal from the photomultiplier was either displayed directly on a digital oscilloscope (Tektronix 2430) for real time measurements or, for spectra recording, fed to a box-car (Stanford SR-250) to be integrated before being digitized by a SR-245 A/D converter. A personal computer was used to record the signal as well as to control and synchronise the whole experiment. The details of the operation of this system have been described elsewhere..$^{29} \mathrm{In}$ short, the monochromator stepper motor was controlled by the computer by means of a driver card D100 from Berger Lahr and the SR-245 interface from Stanford Research. The "busy" output provided by the box-car synchronised the signal coming from the detection system (cell, monochromator, photomultiplier and box-car) with its acquisition, and conducted it to the computer through the RS 232 interface, to be stored with the corresponding wavelength. The process was repeated at the same wavelength as many times as necessary to obtain an acceptable $\mathrm{S} / \mathrm{N}$ ratio. Next, the monochromator moved to a new wavelength $(\lambda+\Delta \lambda)$ and the whole process was repeated until the final wavelength was reached.

Experiments were performed in order to study the dependence of the emissions at 460 and $575 \mathrm{~nm}$ on incident laser intensity. The pump laser intensity was attenuated in a controlled way by intercalating in the pumping beam path different numbers of microscope cover glasses.

\section{Materials and sample preparation}

Benzophenone (Aldrich, 99\%) and Acetonitrile (Scharlau, far UV HPLC grade) were used as received. Triethylamine (Scharlau) was distilled and stored under nitrogen. Sample concentrations were prepared by standard methods. Degassing of the samples was accomplished by the "freeze and thaw method" pumping down to pressures below $10^{-4}$ torr. 


\section{RESULTS AND DISCUSSION}

Irradiation of benzophenone (BZ) in acetonitrile (ACT) at $308 \mathrm{~nm}$ gives a spectrum (Fig. 1a) that can be identified as belonging to phosphorescence of the benzophenone triplet state (experimental conditions are described below). It shows clearly the vibrational progression typical of this emission, and the maximum at $460 \mathrm{~nm}$ coincides with the reported values. ${ }^{30,31 a}$ The dependence of the triplet benzophenone (BZT) lifetime on BZ concentration in ACT, in a range from 1.5 to approximately $20 \mathrm{mM}$, was studied in the first place in order to find the more favourable experimental conditions for further work. It was found that the change in the BZT lifetime was practically negligible for concentrations between 2 and $4 \mathrm{mM}$. So, in the experiments described below the $\mathrm{BZ}$ concentration was maintained between 3.6 and $3.9 \mathrm{mM}$. The emission intensity decay under these conditions (i.e. BZ concentration $=3.9 \mathrm{mM}$ ) is shown in Figure 1b. It exhibits a clear unimolecular behaviour with a lifetime $\tau=25 \pm 1 \mu$ s in good agreement with literature values. ${ }^{32,33}$ In all cases the error quoted corresponds to two standard deviations from the mean.

Under the above experimental conditions, $[\mathrm{BZ}]=3.6-3.9 \mathrm{mM}$, the addition of triethylamine (TEA) in concentrations of the order of $50 \mathrm{mM}$ inhibits completely the BZT phosphorescence and causes the appearance of a strong signal whose spectrum is identical to that reported for the fluorescence emission of the excited benzophenone ketyl radical $\left(\mathrm{BK}^{*}\right)$. Its lifetime is below our quantitative detection limits (i.e. below $10 \mathrm{~ns}$ ), which is consistent with the values reported in the literature. ${ }^{19,34-37}$ At lower TEA concentrations both the BZT phosphorescence and this new emission with the maximum centred at $575 \mathrm{~nm}$ are simultaneously seen (Fig. 2). At first, the new emission appears just as a shoulder on the BZT phosphorescence. Then, its intensity increases as TEA concentration is raised until finally, at high TEA concentrations, it is the only observable emission.

The emission intensities at $460 \mathrm{~nm}$ and at $575 \mathrm{~nm}$, referred to the water Raman band at $340 \mathrm{~nm}$ as internal standard, have been plotted against TEA concentration in Figure 3. The benzophenone phosphorescence decays very fast, a TEA concentration of less than $1 \mathrm{mM}$ is enough to reduce the emission to a level indistinguishable from the experimental background. The emission growth at $575 \mathrm{~nm}$ presents a completely different pattern. It increases slowly and for high TEA concentrations seems to reach a plateau.

In what follows, the laser intensity dependence of the two emissions will be analyzed in the first place. Afterwards, the BZT phosphorescence kinetic behaviour and the $575 \mathrm{~nm}$ band will be studied; finally a mechanism of reaction will be described and modelled in a context that includes all the available information.

\section{Laser intensity dependence of the $460 \mathrm{~nm}$ and $575 \mathrm{~nm}$ emissions}

The probability of biphotonic absorption $\mathrm{W}$ in a sequential process is quadratically dependent $^{38}$ on the laser incident intensity (I),

$$
\mathrm{W} \propto \mathrm{I}^{2} .
$$



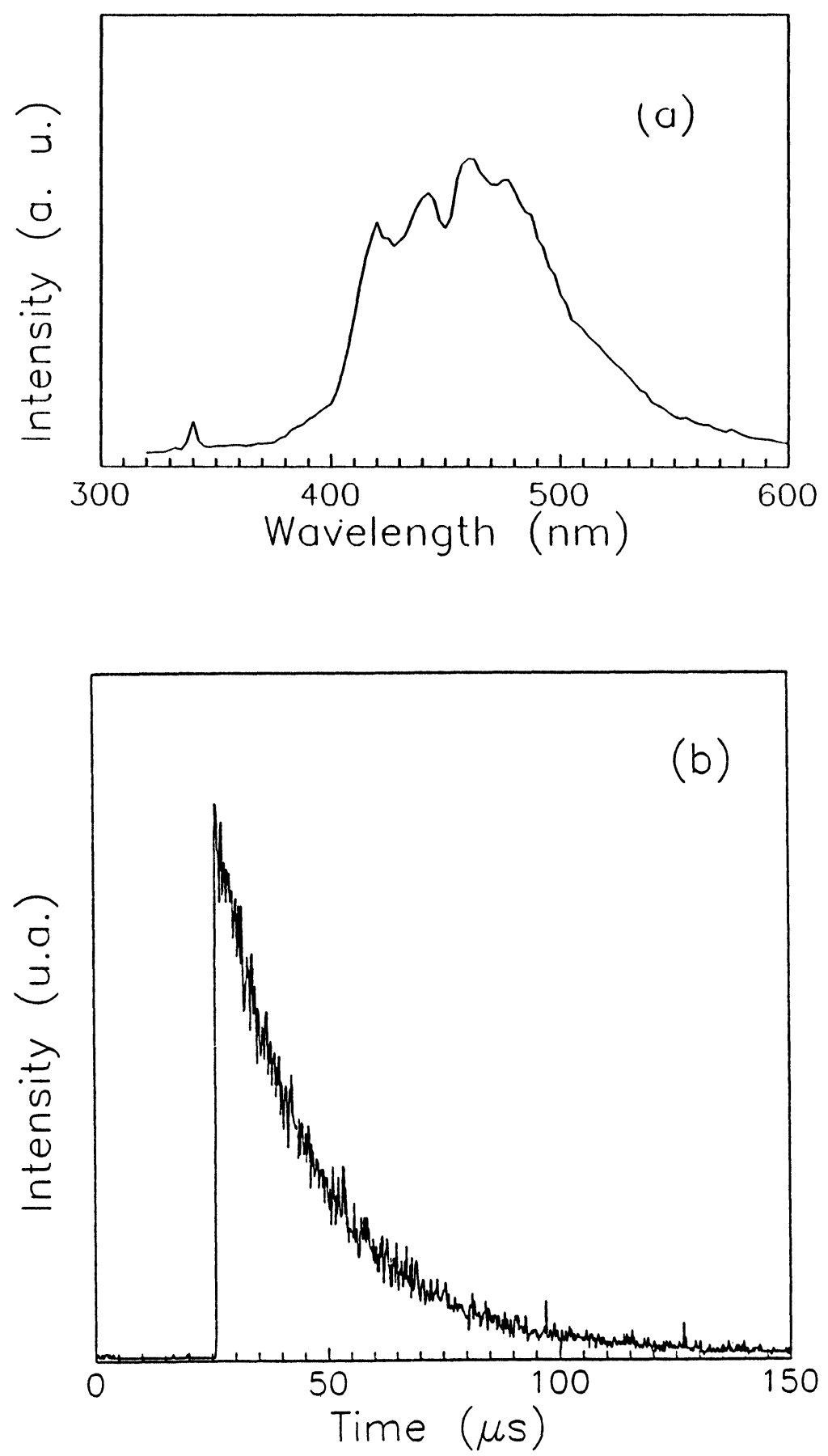

Figure 1 Phosphorescence spectrum (a) and temporal decay of the emission intensity at $460 \mathrm{~nm}$ (b) of a solution of benzophenone in acetonitrile $3.9 \mathrm{mM}$ after laser irradiation at $308 \mathrm{~nm}$. 


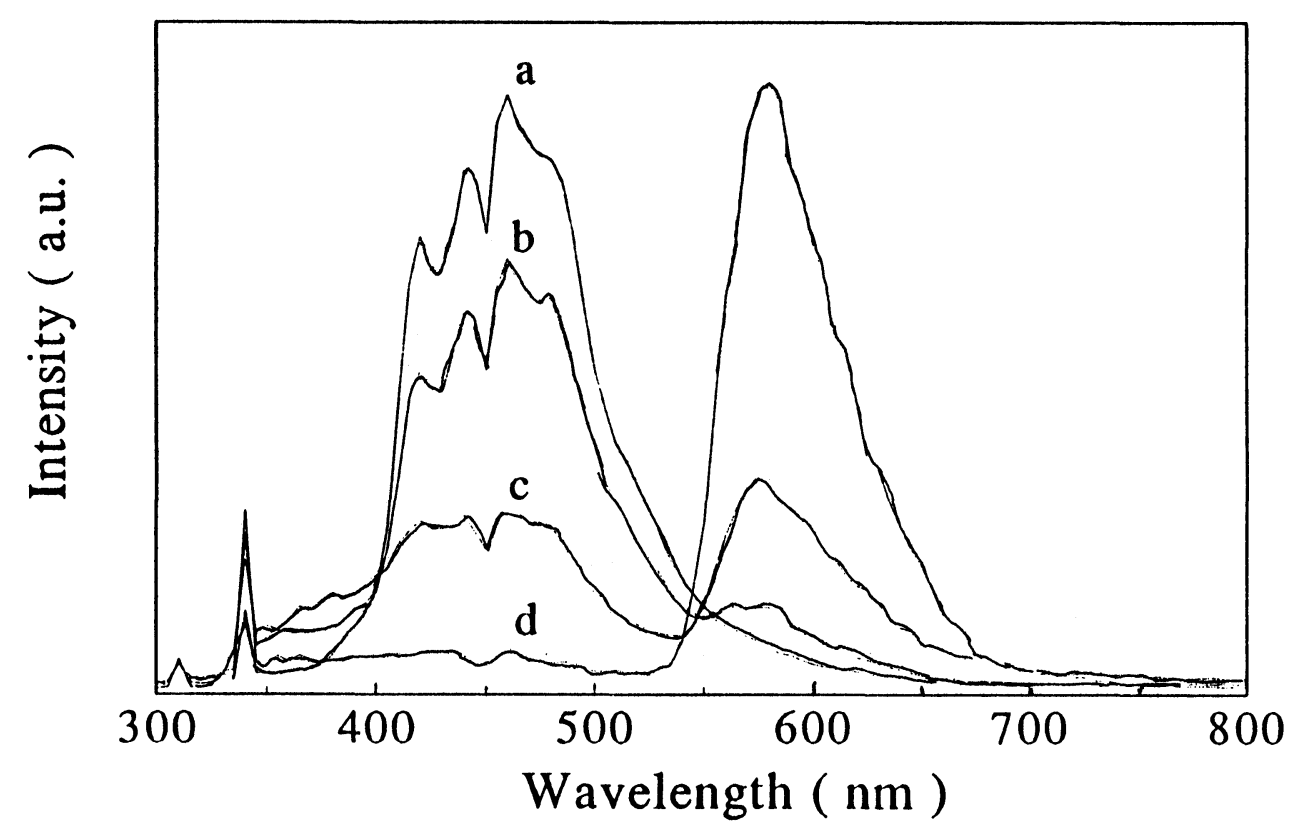

Figure 2 Emission spectra of a solution of benzophenone in acetonitrile $3.9 \mathrm{mM}$ after laser irradiation at $308 \mathrm{~nm}$ with different triethylamine concentrations: a) $0 \mathrm{mM}$, b) $0.02 \mathrm{mM}$, c) $0.7 \mathrm{mM}$, and d) $50 \mathrm{mM}$.

The laser intensity dependence of the $460 \mathrm{~nm}$ emission has been measured in a solution of $\mathrm{BZ}(3.7 \mathrm{mM})$ in ACT while the corresponding study of the emission at $575 \mathrm{~nm}$ was carried out in a solution of BZ/TEA (4/50 mM) in ACT. These concentrations provide the best possible $\mathrm{S} / \mathrm{N}$ ratio. The observed extremely fast quenching of the $460 \mathrm{~nm}$ emission by TEA prevents the analysis of this emission in the presence of even minute amounts of quencher.

The natural logarithms of the observed emission intensities at $460 \mathrm{~nm}$ and $575 \mathrm{~nm}$ have been plotted against the natural logarithm of the incident pumping laser intensity in Figure 4. According to the above equation a sequential biphotonic absorption should yield a straight line with slope 2 . The experimentally obtained slope for the $575 \mathrm{~nm}$ emission is $1.88 \pm 0.06$, close to the theoretically expected value. The error quoted corresponds to one standard deviation of the mean. The discrepancy is of the expected magnitude in this type of measurements in which the pump beam is mildly focused. 39,40 Thus, we can safely conclude that the formation of the excited benzophenone ketyl radical is consequence of a single pulse two photon sequential absorption.

The behaviour of the $460 \mathrm{~nm}$ emission is totally different. The value found for the slope, $0.51 \pm 0.03$, is below the single photon absorption value of 1 . Absorption by the initially formed benzophenone triplet could explain the observed result. ${ }^{41}$ In the absence of TEA, the BZT lifetime is of the order of tenths of microseconds, allowing the fast build up of a relatively high transitory concentration of BZT, making the possibility of the pulsed light absorption by BZT facile. 


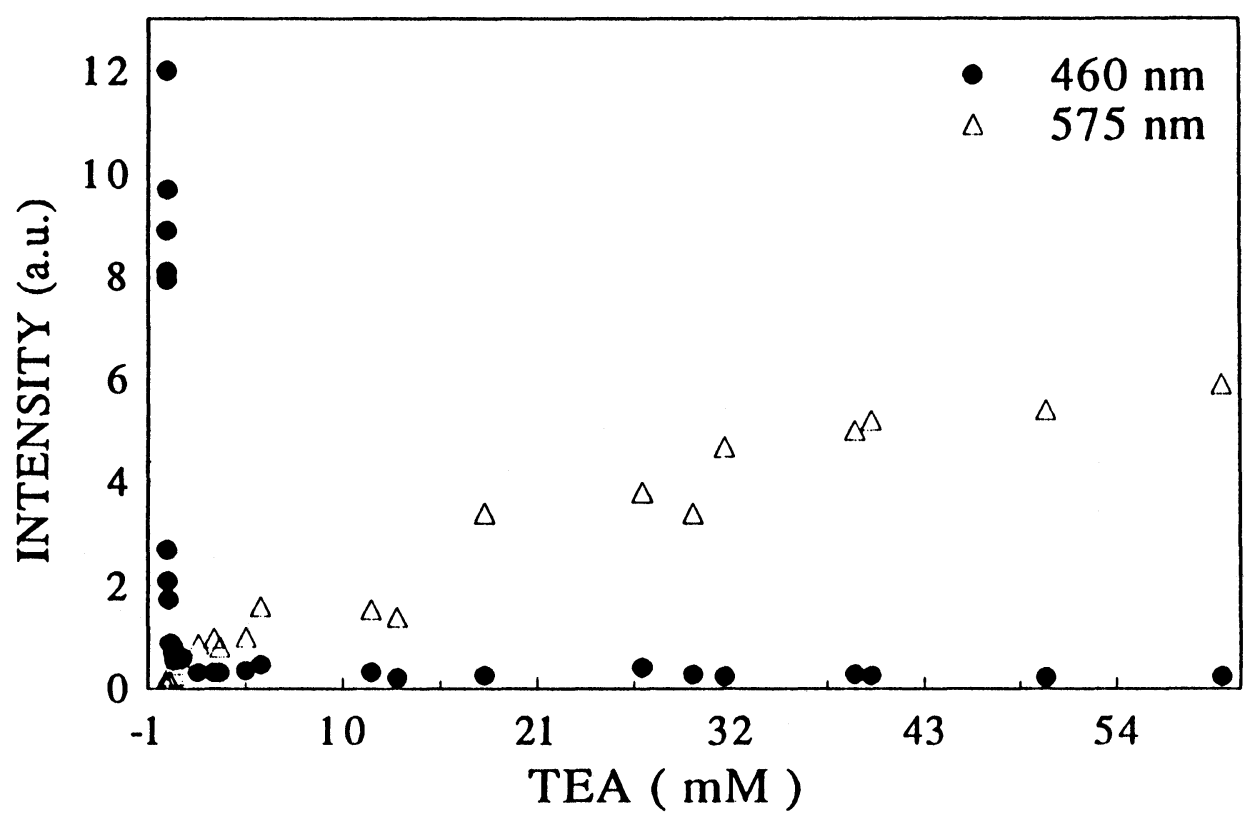

Figure 3 Intensities of the emission from laser irradiated $(308 \mathrm{~nm})$ benzophenone in acetonitrile with added triethylamine at $460 \mathrm{~nm}$ and $575 \mathrm{~nm}$ v.s. triethylamine concentration. The water Raman band at $340 \mathrm{~nm}$ was used as internal standard.

In the experiment with high TEA concentration, where the $575 \mathrm{~nm}$ emission has been analyzed, the quenching of BZT induced by TEA should reduce its lifetime to a few nanoseconds impeeding the BZT population build up, and consequently making the absorption by the triplet very unlikely and therefore, its influence negligible.

\section{Experimental determination of the triplet benzophenone quenching rate constant} by triethylamine

a) Quenching rate constant determination from emission intensities at $460 \mathrm{~nm}$.

The quenching rate constant can be calculated from the emission intensity values using the well known Stern-Volmer equation ${ }^{31 b}$

$$
\mathrm{I}_{0} / \mathrm{I}=1+\mathrm{k}_{\mathrm{Q}}[\mathrm{Q}] / \Sigma \mathrm{k}
$$

where $\mathrm{I}_{0}$ is the emission intensity at $460 \mathrm{~nm}$ in absence of TEA, $\mathrm{I}$ is the intensity at each different TEA concentration, $\mathrm{k}_{\mathrm{Q}}$ is the TEA quenching rate constant, [Q] is the quencher concentration, and $\Sigma \mathrm{k}$ is the sum of deactivation rates in absence of TEA. From the experimentally observed lifetime in absence of TEA $\Sigma k$ can be evaluated, $\Sigma \mathrm{k}=1 / \tau_{0}=(37 \pm 2) \times 10^{3} \mathrm{~s}^{-1}$.

The Stern-Volmer representation (i.e. $\mathrm{I}_{0} / \mathrm{I}$ vs. [Q]) is shown in Figure 5. It can be observed that the least squares fit of the experimental results produces a straight line with reasonable point scattering. The intercept, $0.7 \pm 0.1$, is not far from one, the 


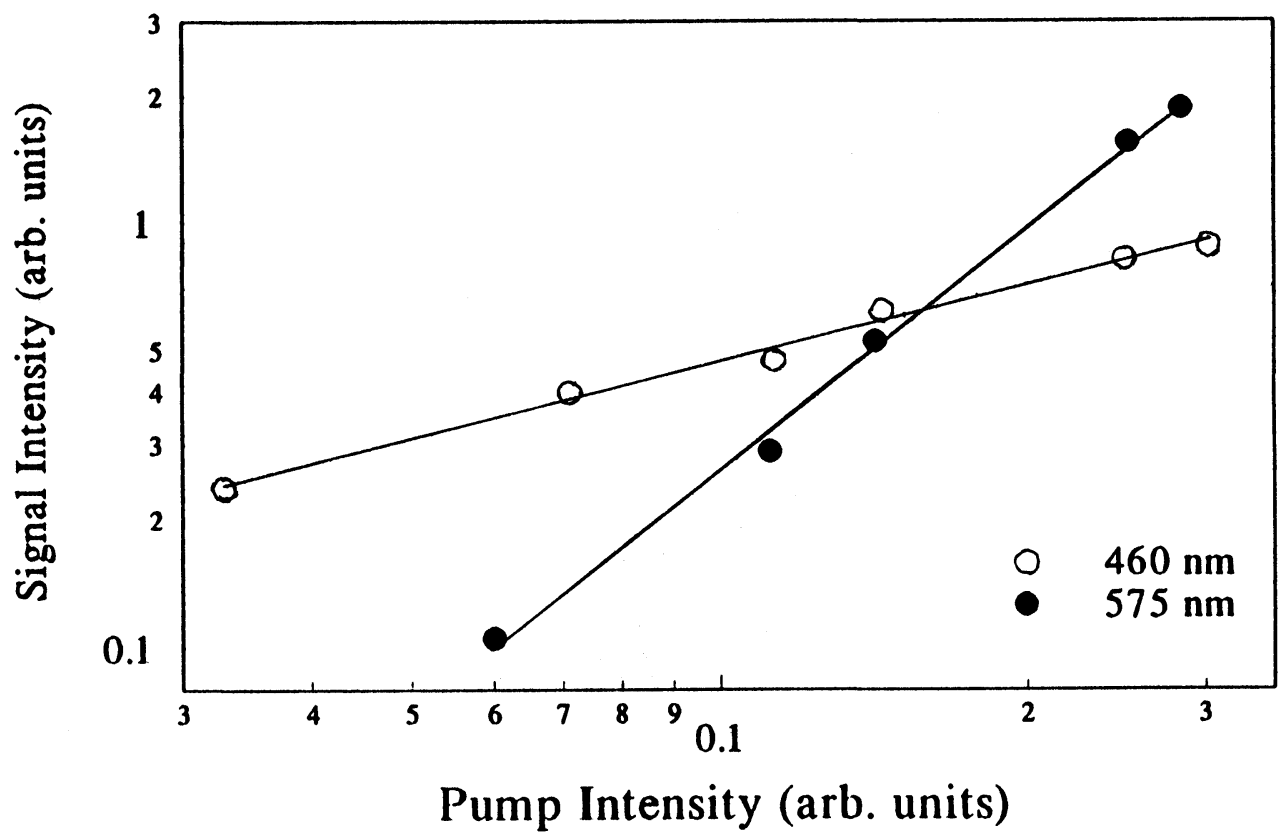

Figure 4 Pump laser intensity dependence of the emission at $460 \mathrm{~nm}(0)$ and $575 \mathrm{~nm}(\bullet)$.

expected value according to the above equation, and the calculated slope is $\mathrm{k}_{\mathrm{Q}} / \Sigma \mathrm{k}=$ $(7.1 \pm 0.7) \times 10^{4} \mathrm{M}^{-1}$. From this value and the previously evaluated $\Sigma \mathrm{k}$ the following quenching rate constant of BZT by TEA is obtained, $\mathrm{k}_{\mathrm{Q}}=(2.6 \pm 0.3) \times 10^{9} \mathrm{M}^{-1} \mathrm{~s}^{-1}$, which is in good agreement with those found in the literature, see below.

b) Quenching rate constant determination from experimental phosphorescence decay rates at $460 \mathrm{~nm}$.

In this case, the Stern-Volmer equation can be written as:

$$
\mathrm{k}_{\mathrm{exp}}=\Sigma \mathrm{k}+\mathrm{k}_{\mathrm{Q}}[\mathrm{Q}]
$$

where $\mathrm{k}_{\text {exp }}$ is the experimentally determined decay rate constant for each quencher concentration [Q] (i.e. [TEA]), and $\Sigma \mathrm{k}$, as previously defined, is the experimental rate of decay in absence of quencher. The representation (Fig. 6) of $\mathrm{k}_{\text {exp }}$ against TEA concentration and the least square fit of the experimental results gave the following result, $\mathrm{k}_{\mathrm{Q}}=(4.0 \pm 0.5) \times 10^{9} \mathrm{M}^{-1} \mathrm{~s}^{-1}$. The ordinate intercept provides the value $\Sigma \mathrm{k}=(35 \pm 6) \times 10^{3} \mathrm{~s}^{-1}$, in good agreement with the above calculated figure.

The discrepancy in the quenching rate constant values obtained by each method could be ascribed to the different systematic errors introduced in each case. Therefore, the preferred figure for the evaluated quenching rate constant of benzophenone triplet phosphorescence by triethylamine would be the averaged value $(3.3 \pm 0.7) \times$ $10^{9} \mathrm{M}^{-1} \mathrm{~s}^{-1}$. 


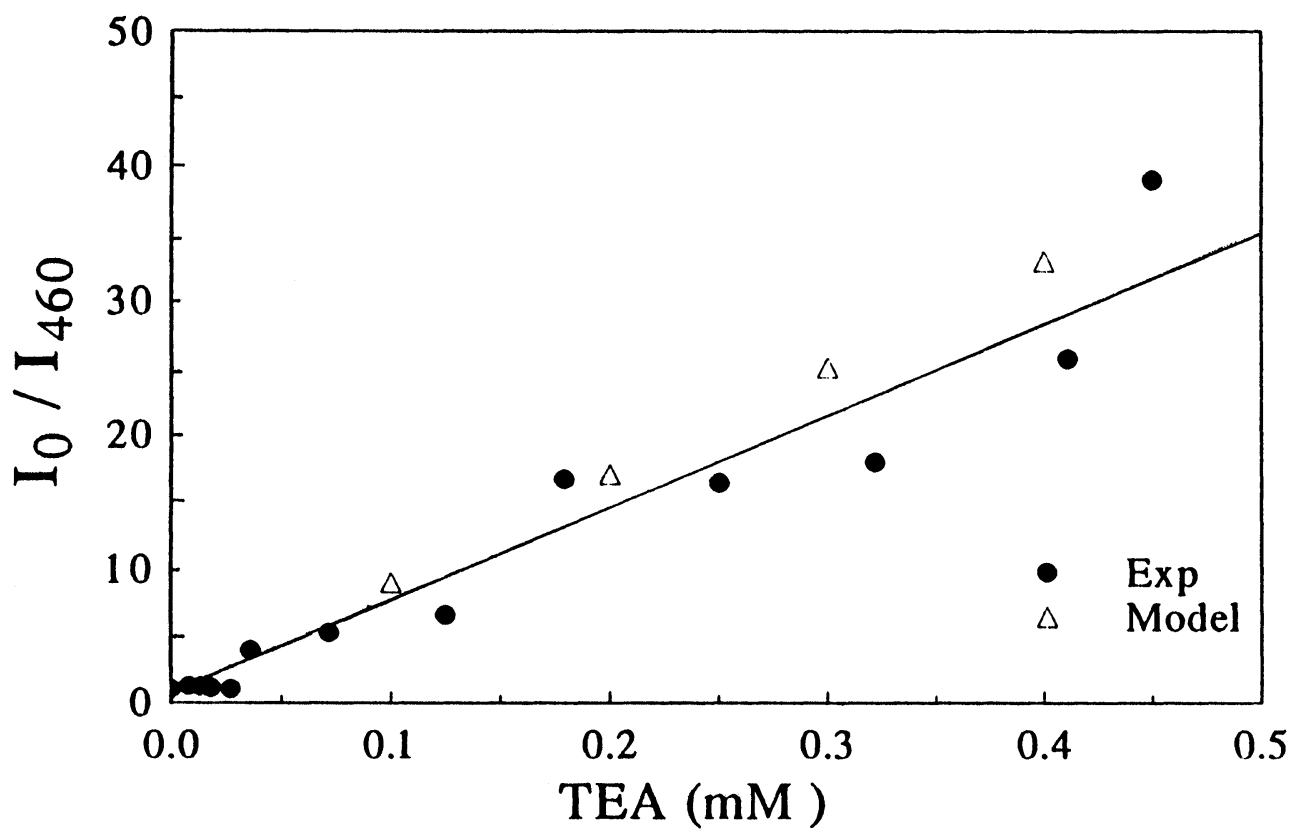

Figure 5 Stern-Volmer representation of the $460 \mathrm{~nm}$ phosphorescence intensity quenching. Full circles "ø" correspond to experimental data and triangles " $\triangle$ " to model calculated data.

The values above mentioned are within the range of values quoted in the literature, $3.2 \times 10^{9} \mathrm{M}^{-1} \mathrm{~s}^{-1}$ by Devadoss et al. ${ }^{18}$ and $3 \times 10^{9} \mathrm{M}^{-1} \mathrm{~s}^{-1}$ reported by Cohen et al.$^{42}$ Turro ${ }^{31 \mathrm{c}}$ gave a value of $2 \times 10^{9} \mathrm{M}^{-1} \mathrm{~s}^{-1}$ but, in this case, benzene was the solvent. In gas phase, Matsushita et al..$^{19}$ found a faster rate constant, $7.8 \times 10^{9} \mathrm{M}^{-1} \mathrm{~s}^{-1}$. This surprising value may indicate that solvation effects may be unnecessary for the electron transfer process in this particular case.

\section{Analysis of the emission at $575 \mathrm{~nm}$}

As previously explained, both the spectrum and lifetime $(\tau<10 \mathrm{~ns}$, our quantitative detection time limit) of the emission centred at $575 \mathrm{~nm}$ agree with those of the transition of the benzophenone ketyl radical from its first electronically excited state to the ground state.

The intensity of the emission at $575 \mathrm{~nm}\left(\mathrm{I}_{575}\right)$ normalized by its maximum value $\left(I_{\max }\right)$, corresponding to the highest TEA concentrations $(50-60 \mathrm{mM})$, has been plotted in Figure 7 against TEA concentration. The behaviour of this emission (Figures 2, 3 ) is quite peculiar. It appears when most of the BZT phosphorescence has disappeared, and slowly increases as TEA concentration is raised until it reaches a quasi saturation for high TEA concentrations. It is evident from the figures that no correlation exists between the BZT emission decay and the $\mathrm{BK}^{*}$ emission growth. 


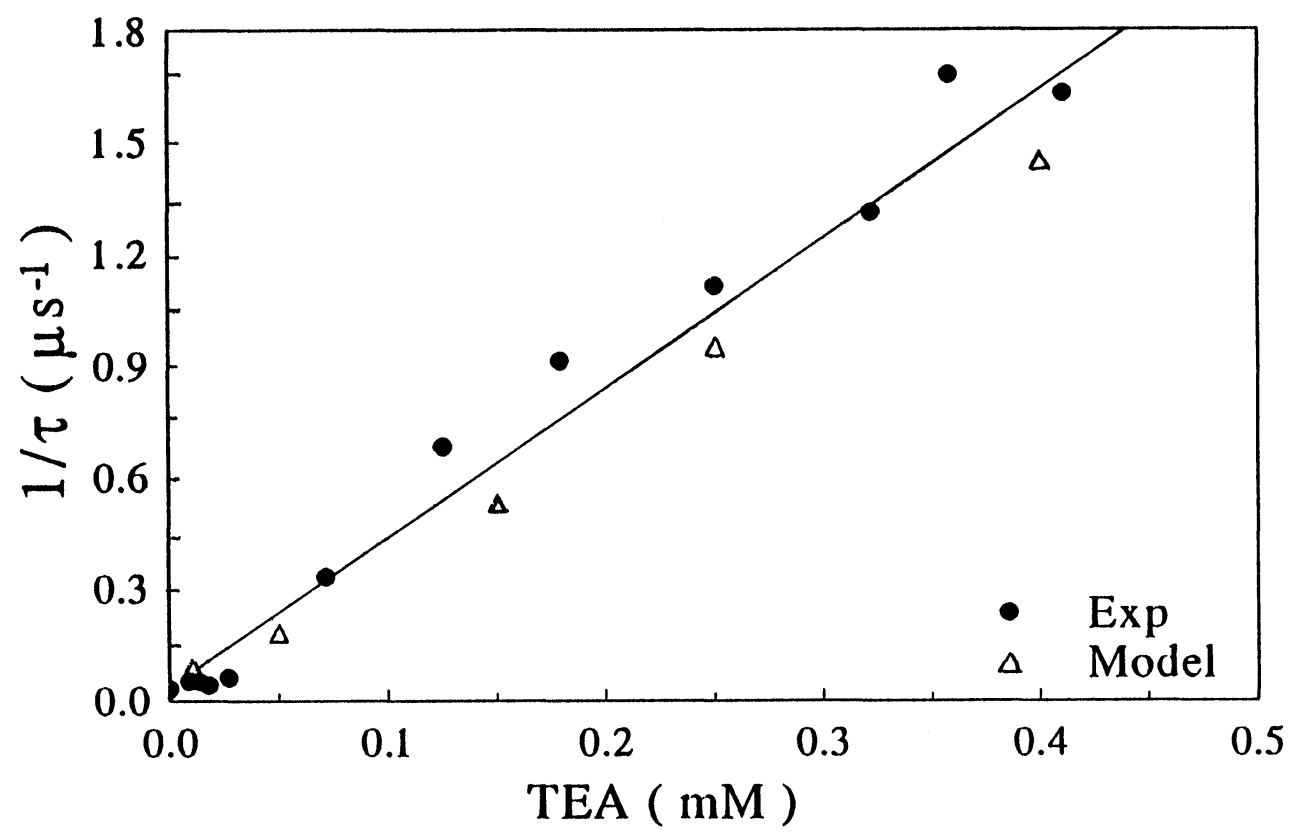

Figure 6 Stern-Volmer representations of experimental decay rates at $460 \mathrm{~nm}$. Full circles "•" correspond to experimental data and triangles " $\triangle$ " to model calculated data.

\section{Mechanistic interpretation and modelling}

An attempt to develop a kinetic model has been carried out. In principle the model should fulfil the following requirements:

1. The excited benzophenone ketyl radical must be formed by a single pulse twophoton absorption assisted reaction process.

2. The quantum yield of benzophenone ketyl radical formation should be the unity under proper conditions (i.e. high enough TEA concentration). ${ }^{17,43-45}$

3 . The model must reproduce within reasonable accuracy the experimental intensities of BZT phosphorescence against TEA concentration (Figure 3).

4. The model should provide BZT intensity decay rates for the different TEA concentrations in reasonable agreement with the experimentally calculated data (Figure 5).

5. The model should give theoretical intensities at $575 \mathrm{~nm}$ (i.e. benzophenone ketyl radical emission) in agreement with those found experimentally (Figure 3).

Several attempts were made before an acceptable model was found. The first requirement reduces the time available for the absorption of the second photon to the duration of the laser pulse.

The second requirement rejects the possibility of any bifurcation in the BZT to $\mathrm{BK}^{\bullet}$ path giving a product different from the ketyl radical. On the other hand, the high BZT quenching rate precludes a fast enough return of the charge transfer com- 


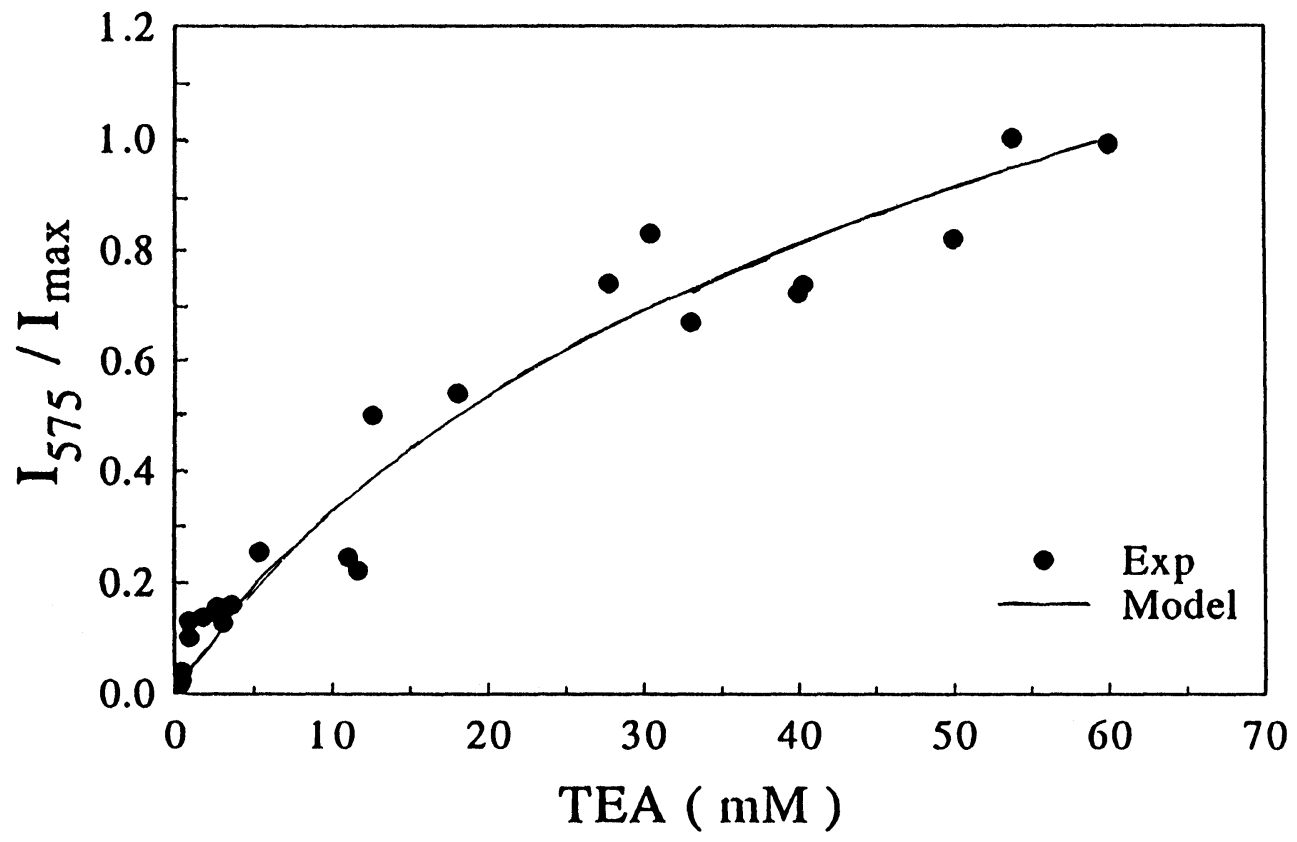

Figure 7 Plot of emission intensities at $575 \mathrm{~nm}$ normalized to its maximum intensity v.s. triethylamine concentration. Full circles "•" correspond to experimental data and the full line to model calculated data.

plex back to the BZT, which would be required by the small dependence of the intensity at $575 \mathrm{~nm}$ on TEA concentration (forward quenching rates higher than diffusion limited would have to be included in order to account for the observed quenching rate constant).

The simplest mechanism able to satisfy all the above experimental requirements is one that includes the biphotonic sequential character of the excited ketyl radical emission. According to this idea the following mechanism may be written:

$$
\begin{aligned}
& \text { BZ } \\
& 308 \mathrm{~nm} \quad \uparrow \mathrm{k}_{\mathrm{ic}} \quad \mathrm{k}_{\mathrm{Q}} \quad \mathrm{k}_{\mathrm{p}} \\
& \mathrm{BZ} \rightarrow \quad \mathrm{BZT}+\mathrm{TEA} \rightarrow \text { (C.T.) } \rightarrow \\
& \downarrow \mathrm{k}_{\mathrm{ph}} \\
& \mathrm{BZ}+\mathrm{h} v(460 \mathrm{~nm}) \\
& \mathrm{BK}^{\bullet}+\mathrm{TEA}^{\bullet} \rightarrow \text { products } \\
& \downarrow \mathrm{k}_{\mathrm{ab}}(308 \mathrm{~nm}) \\
& \mathrm{BK}^{* *} \rightarrow \mathrm{BK}^{\bullet}+\mathrm{h} v(575 \mathrm{~nm}) \\
& \mathrm{k}_{\mathrm{f}}
\end{aligned}
$$

The benzophenone, BZ, forms the benzophenone triplet state, BZT, by absorption of a $308 \mathrm{~nm}$ photon and subsequent intersystem crossing. The BZT can either emit phosphorescence with rate $\mathrm{k}_{\mathrm{ph}}$ or give $\mathrm{BZ}$ directly by internal conversion with rate $\mathrm{k}_{\mathrm{ic}}$. The BZT can also be quenched by triethylamine, TEA, with rate $\mathrm{k}_{\mathrm{Q}}$ forming an intermediary charge transfer complex, C.T., which undergoes internal protonation with rate $\mathrm{k}_{\mathrm{p}}$, producing the benzophenone ketyl radical $\mathrm{BK}^{\bullet}$ and the triethylamine 
radical TEA ${ }^{\bullet}$. The $\mathrm{BK}^{\bullet}$ can absorb a second $308 \mathrm{~nm}$ photon from the laser pulse with rate $\mathrm{k}_{\mathrm{ab}}$ forming the excited benzophenone ketyl radical $\mathrm{BK}^{* *}$, that emits at $575 \mathrm{~nm}$ with rate $\mathrm{k}_{\mathrm{f}}$.

The above mechanism was modelled as follows. The sum of BZT decay rates by internal conversion $\mathrm{k}_{\mathrm{ic}}$ and phosphorescence $\mathrm{k}_{\mathrm{ph}}$ can be reasonably approximated by the experimental decay of BZT in ACT without added TEA, $\mathrm{k}_{0}=\tau^{-1}=(37 \pm 2) \times$ $10^{3} \mathrm{~s}^{-1}$, previously evaluated. The partial contribution of each rate constant is difficult to evaluate exactly for a given set of experimental conditions. Matrix phosphorescence lifetimes ${ }^{30}$ may provide some criteria for partitioning; however, the possible increase of the phosphorescence by specific interactions, between BZT and solvent should be taken into account $t^{44}$. The values used in the model have been $\mathrm{k}_{\mathrm{ph}}=8.4 \times$ $10^{3} \mathrm{~s}^{-1}$ and $\mathrm{k}_{\mathrm{ic}},=2.9 \times 10^{4} \mathrm{~s}^{-1}$. The BZT quenching rate constant used in the model was close to the averaged value previously calculated using the two different SternVolmer approaches, $\mathrm{k}_{\mathrm{Q}}=3 \times 10^{9} \mathrm{M}^{-1} \mathrm{~s}^{-1}$. The protonation rate constant was fixed at $\mathrm{k}_{\mathrm{p}}=6.7 \times 10^{10} \mathrm{~s}^{-1} \cdot{ }^{17},{ }^{45}$ The laser pulse was estimated as a triangular area corresponding to the total number of $308 \mathrm{~nm}$ laser pulse photons incident into the cell and a width (FWHM) of about 10ns. The absorption rate constant was evaluated from the known benzophenone ketyl radical extinction coefficient $\epsilon=3700 \mathrm{M}^{-1} \mathrm{~cm}^{-1}$ at 308 $\mathrm{nm} .{ }^{46}$ The excited benzophenone ketyl radical emission rate constant was obtained from the already mentioned emission lifetime.

The integration of the differential equations set was accomplished by the ACUCHEM program ${ }^{47}$ that is based in the well known variable order, variable step DDRIV integrator, ${ }^{48}$ and provides all the facilities needed. A compatible PC computer was used.

\section{Analysis of the model behaviour}

The model so developed accomplishes all the requirements demanded.

The quantum yield of benzophenone ketyl radical calculated as $\Phi=\mathrm{k}_{\mathrm{Q}}[\mathrm{TEA}] /\left(\mathrm{k}_{\mathrm{Q}}\right.$ [TEA] $+k_{\mathrm{ph}}+\mathrm{k}_{\mathrm{ic}}$ ), and using model values for the different rate constants, is $\Phi=0.986$ for a TEA concentration of $1 \mathrm{mM}$, and reaches 0.9998 for concentrations of $10 \mathrm{mM}$. These figures are in good agreement with the reported value $\phi=1$.

Some calculated values, $\mathrm{I}_{0} / \mathrm{I}_{460}$ have been represented along with the experimental data in the Stern-Volmer plot of the phosphorescence intensity quenching (see Fig. 5). The deviations from the experimental least squared Stern-Volmer straight line are within the experimental errors. Model calculated intensity decay rates, $1 / \tau$, also show a good behaviour, as can be seen in Figure 6 .

The model calculated intensity at $575 \mathrm{~nm}$, represented as a full line in Figure 7 , also is in good agreement with the experimental results.

According to the evidence presented so far, it seems that the biphotonic absorption mechanism properly explains the experimental data obtained for the $308 \mathrm{~nm}$ laser photolysis of benzophenone in the presence of TEA. The model includes, and therefore agrees with, most of the known available data about the system: BZT quenching rate constants, extremely high protonation rate of the intermediate complex, and formation of the BZ ketyl radical. However, the model says little about how the 
included charge transfer complex is formed. The model discards the sometimes mentioned return back to the initial state. This fact coupled with recent gas phase results ${ }^{19}$ may indicate that the charge transfer stabilization is really unimportant in this particular system, and perhaps it could be responsible for the sound behaviour of the system as polymer photoinitiator. Somehow the lack of C.T. stabilization may provide the driving force that induces the fast and efficient protonation pathway leading to the radicals.

The mechanistic description of the single pulse two-photon assisted reaction allows a simple evaluation of the minimum rate constant values involved in the process. Thus, the reaction sequence: absorption of the first photon, formation of the excited singlet $\mathrm{BZ}$, intersystem crossing to the BZT, electron transfer and biradical ion formation, proton transfer, and final BZ ketyl radical absorption of the second photon must occur in less than $10 \mathrm{~ns}$. The possibility of using the single pulse two photon sequential absorption assisted reaction scheme for the investigation of extremely fast reactions could be of interest.

\section{Acknowledgements}

This work has been supported by DGICYT project no. PB90-0071 and CICYT project no. MA91-0488. I. G. M. thanks the CSIC for a Reincorporation Contract. J. D. also thanks the MEC for his grant.

\section{References}

1. A. Ledwith. J. Oil Colour Chem. Assoc., 59, 157 (1976).

2. V. D. McGinniss. Developments in Polymer Chemistry Vol. 3, Applied Science, Barking 1982.

3. C. G. Rofrey. Polymerization of Surface Coatings, Wiley, New York, 1982.

4. S. P. Pappas. U. V. Curing, Science and Technology Vols. I and II, Technology Marketing Corporation, Stamford CT, 1978 and 1985.

5. S. G. Cohen and R. J. Baumgarten. J. Am. Chem. Soc., 87, 2996 (1965).

6. S. G. Cohen and R. J. Baumgarten. J. Am. Chem. Soc., 89, 3471 (1967).

7. S. G. Cohen and H. M. Chao. J. Am. Chem. Soc., 90, 165 (1968).

8. P. J. Wagner and A. E. Kemppainen. J. Amer. Chem. Soc., 91, 3085 (1969).

9. S. G. Cohen, A. Parola and G. H. Parsons. Chem. Rev., 73, 141 (1973).

10. P. J. Wagner. Top. Current Chem., 66, 1 (1976).

11. S. G. Cohen and J. I. Cohen. J. Am. Chem. Soc., 89, 164 (1967).

12. R. F. Davidson and P. F. Lambeth. J. Chem. Soc. Chem. Commun., 511 (1968).

13. S. Arimitsu, H. Masuhara, N. Mataga and H. Tsubomura. J. Phys. Chem., 79, 1255 (1975).

14. A. H. Parola and S. G. Cohen. J. Photochem., 12, 41 (1980).

15. H. Ohtani, T. Kobayoshi, K. Suzuki and S. Nagakura. Nippon Kagaku Kaishi, 10, 1479 (1984).

16. M. Hoshino and A. Shizuka. J. Phys. Chem., 91, 714 (1987).

17. C. G. Schaefer and K. S. Peters. J. Am. Chem. Soc., 102, 7566 (1980).

18. C. Devadoss and R. W. Fessenden. J. Phys. Chem., 95, 7253 (1991).

19. Y. Matsushita, Y. Kajii and K. Obi. J. Phys. Chem., 96, 4445 (1992).

20. B. W. Hodgson, J. P. Keene, E. J. Land and A. J. Swallow. J. Chem. Phys., 63, 3671 (1975).

21. R. Mehnert, O. Brede and W. Helmstreit. Z. Chem., 15, 488 (1975).

22. V. Nagarajan and R. W. Fessenden. Chem. Phys. Lett., 112, 207 (1984).

23. M. R. Topp. Chem. Phys. Lett., 39, 423 (1976).

24. L. J. Johnston, D. J. Lougnot, V. Wintgens and J. C. Scaiano. J. Am. Chem. Soc., 110, 518 (1988).

25. L. J. Johnston, D. J. Lougnot and J. C. Scaiano. Chem. Phys. Lett., 119, 205 (1986).

26. H. Hiratsuka, T. Yamaki, Y. Maekawa, T. Hikida and Y. Mori. J. Phys. Chem., 90, 774 (1986).

27. K. R. Nagvi and U. P. Wild. Chem. Phys. Lett., 41, 570 (1976). 
28. T. F. George. J. Phys. Chem., 86, 10 (1982).

29. M. Rodríguez, M. Martín and J. Ruiz. Meas. Sci. Techn., 3, 229 (1992).

30. N. J. Turro. Molecular Photochemistry, Benjamin, N. Y. 1967, p. 78.

31. N. J. Turro. Modern Molecular Photochemistry, Benjamin, California, 1979.

a) p. 116 and 127 .

b) p. 246 and 247 .

c) p. 378 .

32. R. V. Bensasson and J. Gramain. J. Chem. Soc. Faraday I, 76, 1801 (1980).

33. W. D. K. Clark, A. D. Litt and C. Steel. J. Am. Chem. Soc., 91, 5413 (1969).

34. K. Obi and H. Yamaguchi. Chem. Phys. Lett., 54, 448 (1978).

35. H. Baumamm, K. P. Schumacher, H. J. Timpe and V. Rehak. Chem. Phys. Lett., 89, 315 (1982).

36. Y. Kajii, H. Itabashi, K. Shibuya and K. Obi. J. Phys. Chem., 96, 7244 (1992).

37. J. C. Scaiano. J. Am. Chem. Soc., 114, 9768 (1992).

38. M. Martin Muñoz. Lasers, J. M. Orza (ed) C.S.I.C. press, pg 202, Madrid 1986 and referencies therein.

39. S. Sepiser and J. Jortner. Chem. Phys. Lett., 68, 3999 (1976).

40. I. N. Arutyuyan, G. A. Askar'Yan and V. A. Pogosyan. Soviet Physics JETP, 31, 548 (1970).

41. N. S. Allen, E. Lam, J. L. Kotecha, W. A. Green, A. Timms, S. Navaratnam and B. J. Parsons. J. Photochem. Photobiol., A: Chem., 54, 367 (1990).

42. S. Iubar, H. Linschitz and S. G. Cohen. J. Am. Chem. Soc., 102, 1419 (1980).

43. M. V. Encinas and J. C. Scaiano. J. Am. Chem. Soc., 103, 6393 (1981).

44. W.D.K. Clark, A. D. Litt and C. Steel. J. Am. Chem. Soc., 87, 4293 (1965).

45. M. Hoshino and H. Shizuka. J. Phys. Chem., 91, 714 (1987).

46. R. Bensasson and E. J. Land. Trans. Faraday Soc., 67, 1904 (1971).

47. W. Braun, J. T. Herron and D. K. Kahaner. Int. J. Chem. Kinetics, 20, 51 (1988).

48. R.F. Boisvert, S.E. Howe and D. K. Kahaner. The Guide to Available Mathematical Software (GAMS), PB 84-17135, National Technical Information Service (NTIS), Springfield VA, 12161, 1984. 